\title{
Predictors of low bone mineral density in an Irish cystic fibrosis cohort

\section{Introduction}

Increased life expectancy in patients with cystic fibrosis (CF) has brought about novel challenges in their care.

Cystic fibrosis-related diabetes (CFRD) and osteoporosis represent an increasing burden of disease in these patients as they get older. Furthermore, recent evidence suggests a link between dysglycaemia and loss in BMD in cystic fibrosis.

We sought to determine predictors of low bone mineral density (BMD) in a cohort of patients attending the Cystic Fibrosis Unit, Beaumont Hospital, Dublin. In particular, we aimed to determine whether dysglycaemia is a significant risk factor.

\section{Methods}

Retrospective review of patients in CF database.

Patients had three monthly assessments of $\mathrm{BMI}$ and $\mathrm{FEV}_{1}$ and annual Dual-Energy X-ray Absorbimetry (DEXA) scan and Oral Glucose Tolerance Test (OGTT).

Data recorded included patient demographics and anthropometric characteristics, biochemistry, BMD as measured by DEXA, lung function, antibiotic courses and number of hospitalisations (expressed as mean $\pm S D)$.

Patients were classified as having either normoglycaemia or dysglycaemia (CFRD or impaired glucose tolerance; WHO criteria).

Impact of patient characteristics on BMD was analysed by Chi square tes for discrete variables and student's $t$ test for continuous variables. Spearman correlation between patient variables and $Z$ scores was calculated.

\section{Results}

Complete data available for 92 patients (Table 1)

63 patients (68\%) had a Z-score $\leq-1$ and $17(18 \%)$ had a Z-score $\leq-2.5$

Lower Z-scores associated with (Figure 1):

- poorer lung function

-low body weight

-higher rates of hospitalisation and antibiotic use

No association between low Z score and dysglycaemia (Table 2 )

Fifty one $(55 \%)$ patients had normal glucose tolerance with HbA1c 36 $\pm 5 \mathrm{mmol} / \mathrm{mol}$ and Z-score $-1.4 \pm 1.2$

Of the 41 dysglycaemic patients, 12 (13\%) had impaired glucose tolerance with $\mathrm{HbA} 1 \mathrm{c} 41 \pm 4 \mathrm{mmol} / \mathrm{mol}$ and $\mathrm{Z}$ score $-1.4 \pm 1.0$. Twenty-nine $(32 \%)$ had CFRD with $\mathrm{HbA} 1 \mathrm{c} 61 \pm 19 \mathrm{mmol} / \mathrm{mol}$ and $\mathrm{Z}$ score $-1.4 \pm 1.5$

\begin{tabular}{|c|c|c|c|c|}
\hline & $\begin{array}{l}\text { Total } \\
n=92\end{array}$ & $\begin{array}{c}\text { Normoglycaemic } \\
n=51\end{array}$ & $\begin{array}{c}\text { Dysglycaemic } \\
\qquad \mathrm{n}=\mathbf{4 1}\end{array}$ & P value \\
\hline Age (yrs) & 25.3 & 25.3 (17 to 62$)$ & 25.1 (18 to 45$)$ & 0.2 \\
\hline $\mathrm{HbA} 1 \mathrm{c}(\mathrm{mmol} / \mathrm{mol})$ & $49 \pm 18$ & $36 \pm 5$ & $58 \pm 15$ & 0.02 \\
\hline BMD (Z score) & -1.5 & $-1.8 \pm 1.2$ & $-1.5 \pm 1.4$ & 0.4 \\
\hline $\mathrm{BMI}\left(\mathrm{kg} / \mathrm{m}^{2}\right)$ & 20.9 & $20.8 \pm 4.3$ & $20.8 \pm 2.7$ & 0.2 \\
\hline $\mathrm{FEV}_{1}$ & 64 & $67 \pm 28.2$ & $54 \pm 24.7$ & 0.02 \\
\hline $\begin{array}{c}\text { Pancreas } \\
\text { Insufficiency (n) }\end{array}$ & 75 & 35 & 40 & 0.004 \\
\hline $\begin{array}{c}25(\mathrm{OH}) \text { Vit D } \\
(\mathrm{nmol} / \mathrm{l})\end{array}$ & 42.7 & $46 \pm 28.5$ & $42.5 \pm 25.4$ & 0.3 \\
\hline Weeks in hospital & 4.2 & $5.5 \pm 15.1$ & $2.8 \pm 6.1$ & 0.1 \\
\hline
\end{tabular}
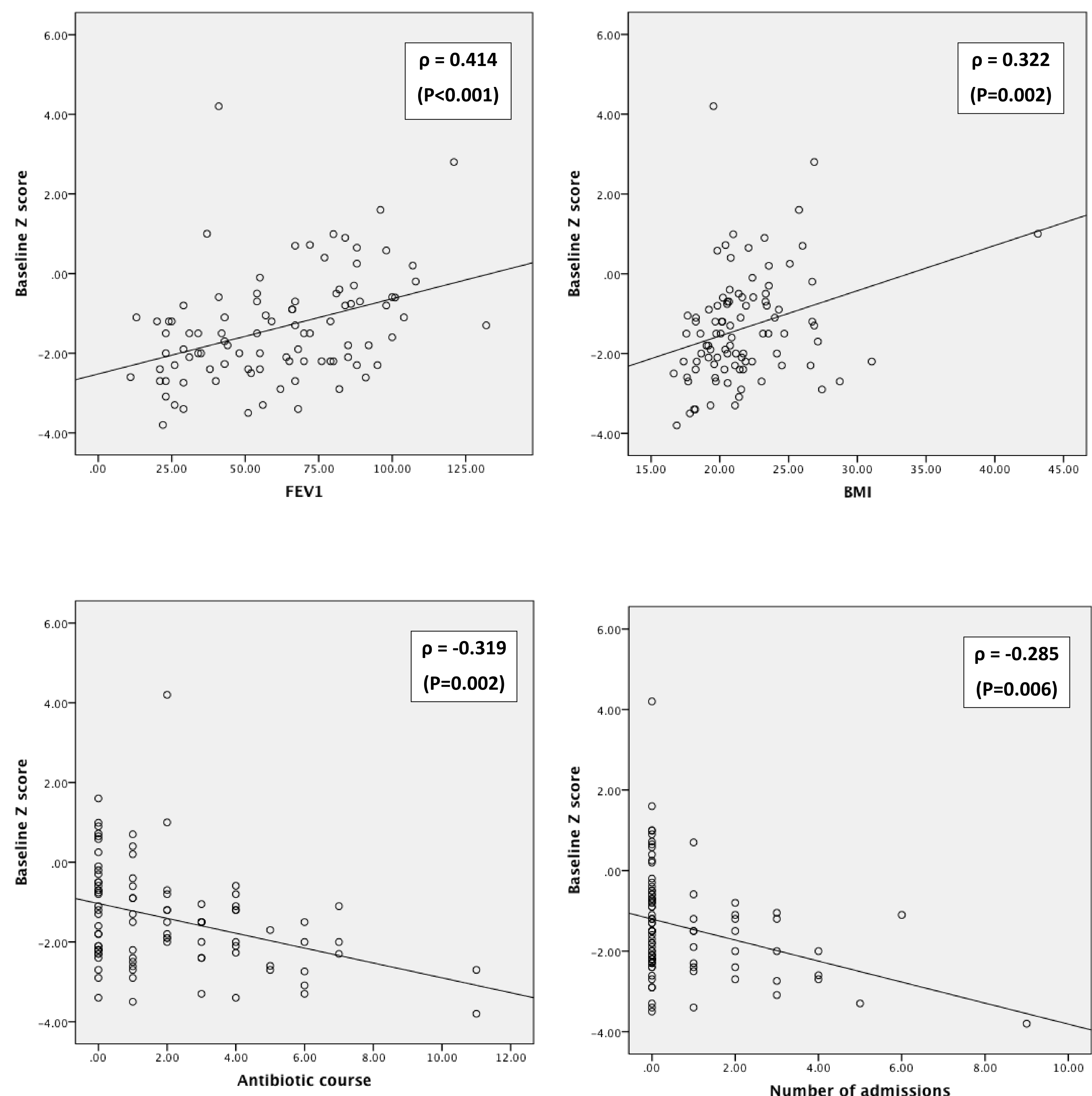

Figure 1: Z score correlation with health indicators

\begin{tabular}{|c|c|c|c|}
\hline & Normoglycaemia & Dysglycaemia & P Value \\
\hline $\begin{array}{c}\text { Median Z } \\
\text { score }\end{array}$ & $-1.8( \pm 1.21)$ & $-1.5( \pm 1.39)$ & 0.35 \\
\hline Z Score $\leq-1$ & $36(71 \%)$ & $27(66 \%)$ & 0.627 \\
\hline Z Score $\leq-2$ & $23(45 \%)$ & $15(37 \%)$ & 0.411 \\
\hline
\end{tabular}

Table 2: Patient BMD stratified by glycaemic status

\section{Discussion}

Osteoporosis in CF is associated with significant morbidity and is an exclusion criterion for lung transplantation.

Numerous factors contribute to decreased bone mineral density; poor nutrition, low BMI, lack of physical exercise, hypogonadism and steroid use. The systemic inflammatory response triggered by recurrent respiratory tract infections also contributes to bone loss.

Dysglycaemia in CF has been shown to be associated with poorer $\mathrm{FEV}_{1}$ and lower BMI, both critical health indicators in these patients. Mortality is increased by up to six-fold in patients with CFRD.

It is physiologically plausible that CFRD should result in osteoporosis. Insulin has an anabolic effect on bone. Furthermore, it has been suggested that hyperglycaemia has a direct weakening effect on bone.

Despite recent evidence, we found no significant association between dysglycaemia, defined as impaired glucose tolerance or CFRD, and low BMD.

$\mathrm{BMI}$, low $\mathrm{FEV}_{1}$ and number and duration of antibiotic courses and hospitalisations were more strongly predictive of bone loss.

Dysglycaemia is associated poor prognosis but does not appear to be a major risk factor for osteoporosis in our cohort of Irish CF patients. 